Cold flow defects in zinc die casting: prevention criteria using simulation and experimental investigations

Armillotta, Antonio; Fasoli, Simone; Guarinoni, Alessandro

This is a post-peer-review, pre-copyedit version of an article published in INTERNATIONAL JOURNAL OF ADVANCED MANUFACTURING TECHNOLOGY. The final authenticated version is available online at: http://dx.doi.org/10.1007/s00170-015-7959-4

This content is provided under $\underline{\text { CC BY-NC-ND } 4.0}$ license

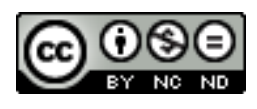




\title{
Cold flow defects in zinc die casting: prevention criteria using simulation and experimental investigations
}

\author{
Antonio Armillotta ${ }^{1 *}$, Simone Fasoli ${ }^{2}$, Alessandro Guarinoni ${ }^{1}$ \\ ${ }^{1}$ Dipartimento di Meccanica, Politecnico di Milano, Via La Masa 1, 20156 Milano, Italy \\ ${ }^{2}$ Bruschi SpA, Via Mendosio 26, 20081 Abbiategrasso (MI), Italy \\ * Corresponding author: \\ e-mail: antonio.armillotta@polimi.it \\ tel.: +3902 23998296 \\ fax: +390223998585
}

\begin{abstract}
High-pressure die casting of zinc alloys is increasingly used in the manufacturing of parts with high aesthetic value. These parts must comply with strict requirements on surface quality, which are generally overlooked in traditional mechanical applications. Cold flow defects, which are a primary concern for surface quality, originate from several different causes that have not yet been fully understood. This report investigates the factors that influence cold flow defects and the choices that can lead to an improvement in surface quality. The research method is based on a case study performed at a die casting company. First, an existing process has been analyzed using simulation to explain the causes of cold flow defects observed in production samples. The temperature at the end of the cavity fill has emerged as a key index for the occurrence of defects, which can be controlled by three primary process parameters: injection velocity, temperature of the cooling medium, and lubricant spraying time. These same factors are then assessed using experimental tests on an existing die, where the number of defects in the selected regions of the casting has been evaluated by image processing. The results suggest that the surface quality can be particularly improved by increasing the flow rate of the molten metal through the gates and avoiding excessive flow turbulence in the wide cavity sections. Consequently, the increase in the gate area has been identified as a specific criterion for the die design. These findings have been validated in the redesign of the die and the selection of the process parameters, which have resulted in a significant reduction in the surface defects.
\end{abstract}

Keywords: die casting, zinc alloy, surface quality, cold shuts, simulation, design for manufacture. 


\section{Introduction}

Traditionally used to manufacture functional parts for frames and mechanisms, high-pressure die casting is increasingly being used to fabricate aesthetic parts in various products, including cars, lighting devices, pieces of furniture, household appliances, and fashion accessories. Zinc alloys [1] are widely used for these applications due to their high fluidity in the molten state, high solidification rate and low thermo-chemical aggressiveness on the die. Such properties allow them to reproduce thin walls and fine details with low shrinkage porosity and good surface finish while keeping process and tooling costs to a minimum.

Additional requirements for ornamental parts include low roughness (surface finish) and lack of visible defects (surface integrity). Although both properties are needed for product acceptance, surface defects are critical because they are enhanced by certain coating processes (e.g., electroplating) and are difficult to remove by polishing or tumble finishing [2]. Therefore, a high surface integrity must be directly achieved as a result of the die casting process at a reasonable compromise of the operating costs. Thus, it is essential to understand the root causes of the defects occurring during cavity filling and early solidification phases (cold flow defects). These defects depend on several process variables, whose effects and interactions are only partially explained $[3,4]$.

The current study analyzes potential strategies to reduce cold flow defects in zinc die castings, selects the most effective ones and verifies their practical application. This report focuses on certain aspects that have not yet been widely discussed, such as the predictability of defects through simulation, the experimental evaluation of the number of defects, and the explanation of the interactions among the process parameters. The study is based on an industrial case, where it can be demonstrated that the cold flow defects can be reduced through general criteria derived from the simulation and experimental tests.

In the next subsections, the specific objectives of the study are discussed after reviewing a few fundamental issues related to surface integrity from the available literature.

\subsection{Background and literature}

The general guidelines for the diagnosis of defects in die castings are provided in several textbooks and technical papers, e.g. [3-6], and with explicit reference in certain cases to the hot-chamber process for zinc alloys $[7,8]$. The objective of developing corrective actions for a wide range of situations has led several researchers to thoroughly investigate the formation and the control of defects. Most of the focus has been on the structural defects and the surface defects from die wear, which are beyond the scope of this report; citing only a few references from a broad range of literatures, they include gas and shrinkage porosity [9], degradation of mechanical properties [10,11], and soldering, heat checking and erosion $[12,13]$.

Cold flow defects at various degrees of severity are significantly more relevant for aesthetic parts in zinc alloys, e.g., color alterations (flow marks) micro-cavities (shotting), narrow grooves (cold shuts) and catastrophic fill failures (laminations, misruns). These defects are commonly caused by the premature solidification of metal during the cavity fill, which prevents different metal streams from welding completely [7]. The cold flow defects are exacerbated by atomization, metal oxidation and entrapment of die lubricant residues, and they are not easily removed during polishing or leveled by protective coatings, which instead tends to enhance them into sharper, more visible flaws.

Similar to any type of casting defect, cold flow defects have metallurgical causes that emphasize the role of molten metal fluidity [14]. This topic has been studied with a particular focus on melt handling procedures [15] and the control of the alloy compositions [16]. The fluidity of the zinc alloys has been shown to depend on the contents of certain alloy elements (aluminum and magnesium) and contaminants (iron, lead, tin, and cadmium), with the proposal of optimized compositions [17]. 
Understanding the phenomena that occur during the cavity fill is a prerequisite to any hypothesis on the formation of cold flow defects. If the cavity were completely filled before the start of solidification, the thermal gradient across the wall thickness would create a uniform solidification front with perfect welding of the opposing metal streams (Fig. 1a). However, a thin solid layer is likely to develop immediately in the last places to fill, where the alloy has a lower temperature; when the molten metal fills the voids among the solid layers, its fluidity may be insufficient for it to be completely welded to previously solidified regions (Fig. 1b). This results in small surface depressions, which degenerate into cracks (cold shuts) due to solidification shrinkage and melt pressure from inside. Atomization can have an additional influence because tiny droplets are more prone to premature solidification, resulting in point-like defects (shotting). Turbulence and obstacles to the flow as well as contaminants (lubricant, oxide) could influence the size of the defects and extend them to wider areas (flow marks).

Based on the above evidence, one fundamental objective is to identify the conditions that lead to visually unacceptable defects. The available results are derived from experimental investigations on aluminum alloys. In [18], it is stated that surface defects are correlated to the heat transfer coefficient between the alloy and the die, which depends on oxidation and turbulence. In [19], the defects are shown to occur below a threshold of the die surface temperature. In [20], tests with different injection temperatures indicate that the formation of a slurry of dendrites (mushy solidification) cause long-freezing alloys to be less prone to cold flow defects; for short-freezing alloys, the criticality seems to depend on the thickness of the early solidified layers (with a possible threshold of approximately $0.2 \mathrm{~mm}$ ).

One additional conjecture, which will be discussed in the current study, is that cold flow defects occur when the metal temperature at the end of the cavity fill, which can be estimated by simulation, decreases below a given threshold. In literature, simulation has been proposed as a tool to predict the occurrence conditions of different types of die-casting defects. Fill simulations are demonstrated on zinc alloys in [21] without explicit reference to the cold flow defects. Elsewhere, researchers have focused on aluminum and magnesium alloys, which are more commonly used for automotive structural parts. The simulation results are primarily concerned with the fill pattern [22], air entrapment in the shot sleeve [23, 24], shrinkage defects in the hot spots [25, 26], and microstructural defects affecting the tensile properties [27, 28]. With the exception of a single attempt to optimize the process parameters and avoid long fill times [29], few simulation studies have a direct relation to the cold flow defects. This lack of research is due to the difficulty of the Eulerian approaches in simulating free flows with high turbulence and atomization, which are likely to be critical for the cold flow defects. A few Lagrangian approaches have thus been tested and developed into prototype software tools, including smoothed particle hydrodynamics [30] as well as a droplet formation model based on the balance of surface tension, pressure and drag forces [31].

Another question that arises is how to measure the number of surface defects. As noted in [32], surface roughness does not consider the numerous types of defects that affect the visual appearance of die castings. Image processing techniques, which are also used in this study, have already been proposed for the creation of defect catalogues [33] and the detection of sub-surface defects after machining [34]. The scanning of casting surfaces by laser triangulation has been used in [35] for a three-dimensional reconstruction of the defects. Die surface temperature, which is known to be correlated to several types of quality issues, including cold flow defects, has been measured using thermocouples [36] and infrared thermography [37].

The influence of the process parameters on certain types of defects has been investigated through experimental plans guided by statistical methods or models based on neural networks. Although most studies are focused on porosity, e.g. [38], the quality measures considered in certain cases are somehow related to the cold flow defects, such as the complete cavity fill and surface roughness. In [39], the need to avoid misruns in zinc castings leads to optimal combinations of metal and die temperatures as well as injection pressure. In [40], similar results were achieved for aluminum alloys. In [41], the roughness of die-cast specimens in a magnesium alloy is shown to depend on factors related to filling (slow and fast shot 
velocities, and die temperature). The quality response tested in [42] is an index related to the overall number of the different types of surface defects (misruns, cold shuts, hot cracks, and soldering).

As discussed in the following sections, nearly every aspect of the die casting process plays a role in the prospective strategies used to reduce the cold flow defects. The injection parameters (operating pressure, plunger velocity, plunger diameter, and gate area) have been set through methods based on the simplifying assumptions of the melt flow, such as the $\mathrm{PQ}^{2}$ diagram and its modifications [43]. The optimal size and location of the runners and gates has been investigated through rules [44], predictive models [45], and CADbased procedures $[46,47]$. Internal cooling systems have been optimized using simulations and experimental tests for different design issues, including the heat transfer coefficient between the die steel and the cooling medium [48], size of the channel sections [49], use of non-circular and variable-size channels [50], use of high-conductivity die materials [51], and design of conformal channels in the tool inserts [52]. External cooling has been studied using the temperature and thermal flow measurements of the heated specimens in hot-worked steel [53] or a heat flux sensor [54] to identify operating windows of the die surface temperature and the die spray parameters. The amount of backpressure due to inadequate venting has been calculated as a function of the vent area [55], vent thickness [56] and fill time [57]; the use of vacuum systems has been occasionally considered for backpressure calculations [58] along with broader discussions of its advantages and limitations [59].

\subsection{Objectives}

It is apparent from the above review that the cold flow defects in die castings have been studied less compared to other types of defects, which are related more to the structural requirements of traditional destination sectors. The few available studies report experimental results on aluminum and magnesium castings, which have considerably different physical properties than those of zinc alloys. Due to the complexity of the phenomena that are thought to cause cold flow defects (turbulent and atomized flow, cooling, solidification and possible remelting, oxidation, and mixing with lubricant), defect reduction strategies cannot be immediately extended among different materials, which justifies the interest towards collecting data and criteria for alloys that are more suitable to applications with high aesthetic requirements.

In addition to exploring possible material-dependent issues, the current study is focused on design choices that can help reduce the cold flow defects. A few specific objectives can be formulated in this direction:

- understand how the occurrence of cold flow defects can be predicted through the simulation of the die casting process in addition to other types of defects discussed in literature;

- identify the process parameters with the most influence on cold flow defects and explain their effects with consideration of possible interactions (typically neglected even if potentially relevant due to the coupling of thermal and fluid flow phenomena); and

- formulate a set of criteria that could help avoid cold flow defects in the product and die design process so that the surface quality of castings do not rely entirely on the search for the optimal settings of the process parameters.

\section{Materials and methods}

The die-casting process for a product with strict requirements of surface quality was used as a reference. In the first phase, starting from an existing configuration of the die and process, a simulation was used to identify the causes of defects in selected regions of the casting. After contemplating the process parameters that could be involved, the attention was focused on a limited set of influential factors to be experimentally tested on sample process batches. The effects of different combinations of factors were evaluated by measuring the amount of surface defects through image processing. Although the selections in each phase 
were guided by the results of the preceding ones, the development of the work as a whole is reported below, and the description of the results for individual phases are provided in the next section.

\subsection{Reference case}

The part in consideration (Fig. 2) is the outer casing of the boiler assembly for a commercial espresso machine, and it is manufactured for nearly 5000 pieces per year by Bruschi SpA (Abbiategrasso, Italy). The material used is Zamak 5 (ASTM AC41A, UNS Z35531), and the average wall thickness is $3 \mathrm{~mm}$. The part is produced on a $2200 \mathrm{kN}$ hot-chamber die-casting machine with a plunger diameter of $80 \mathrm{~mm}$. The die (Fig. 3a) has a single cavity machined in two inserts of H11 hot-work steel (DIN 1.2343), which has a front size of $260 \times 290 \mathrm{~mm}$ and a height of $165.5 \mathrm{~mm}$ (ejector die half, Fig. 3b) and $120 \mathrm{~mm}$ (cover die half, Fig. 3c). The gating system consists of a sprue and four tangential runners in the central aperture of the part. The cavity has six overflows, four of which are connected to two vacuum valves activated immediately before the start of the fast shot stage.

The initial set of process parameters includes a metal temperature of $420^{\circ} \mathrm{C}$ (compared to a melting range of $380-386^{\circ} \mathrm{C}$ ), operating pressure of $26 \mathrm{MPa}$, and fast-shot plunger velocity of $0.76 \mathrm{~m} / \mathrm{s}$. The die is internally cooled by oil at $130^{\circ} \mathrm{C}$ in the cover die half and water at $20^{\circ} \mathrm{C}$ in the ejector die half; the cooling system includes five circuits and a tube-style fountain (Fig. 3d). A die lubricant is sprayed through die-mounted nozzles for $0.4 \mathrm{~s}$. The dwell time is $5.5 \mathrm{~s}$ within a total cycle time of $24 \mathrm{~s}$. The secondary phases after die casting include manual trimming, tapping of screw holes, polishing and electroplating.

During early production runs, a visual inspection revealed the frequent occurrence of cold shuts in welldefined zones on the top side of the casting, which are denoted as 1, 2, 3 and 4 in Fig. 4a. The defect is shown over a wide area of zone 4 in Fig. 4b, and with 10x magnification in Fig. 4c. The cold shuts cannot be leveled in the polishing phase and remain partially visible after electroplating. Additional surface defects eliminated in earlier production tests included deposits from the lubricant buildup in zone 5 and visible flow lines due to turbulence in zone 6. An increase in the die temperature was not suitable to avoid the above defects due to the risk of warping, which is critical for the position accuracy of screw holes 7 and 8 .

These types of defects are typically attributed to several causes. Excluding the defects related to material and geometry (e.g., alloy composition, melt cleanliness, and flow distance), there are primarily three processrelated causes. First, a small fraction of the metal solidifies before the end of the fill and does not completely weld with regions that solidify later; this problem can arise under several conditions, which include low metal temperature, overcooling of the die, and long fill time due to insufficient metal flow rate during injection. Secondly, flow detachments and impacts can occur in a turbulent flow of coarse droplets; this condition is related to insufficient atomization, which is favoured by low gate velocity and air backpressure due to poor venting. Lastly, the flow can be contaminated by oxide as well as vapor and combustion residues; the latter two are related to die lubrication issues, which include excessive amounts, buildup in cavity recesses, incomplete evaporation of the water fraction (due to low die surface temperature) and coking of the oil fraction (due to high die temperature, unlikely for Zamak alloys). The above issues involve a large number of variables, each of which is subject to compromises with other needs of the process (e.g., protection against die erosion, soldering, and drags).

\subsection{Process simulation}

The premise for achieving a good surface integrity of the die castings is that cold flow defects can be predicted using simulations of cavity fill under different process parameters and die configurations. Although flow simulation is primarily used to predict misruns and porosity, it also provides estimates of certain parameters that are thought to be related to cold flow defects, which include metal and die temperatures, 
magnitude and direction of the metal velocity, flow distance, and location of regions that fill last. This output could be used for predicting defects provided that the threshold values or the critical combinations of the simulated parameters are identified. In the case under consideration, these can be determined by comparing the simulation results with the number and position of the actual defects in the product samples.

Thus, a computer model of the process was built using the MAGMA ${ }^{\circledR} 5$ simulation software. It included a finite-volume mesh of the cavity and the cooling system as well as the specifications of the die casting machine and the initial setting of the process parameters. The high detail and resolution of the model was intended to achieve the best reasonable accuracy to estimate the flow and cooling patterns during the cavity fill. However, the following simplifying assumptions were inevitably accepted due to computational constraints: a) the die spray is only modeled through an a priori estimate of its cooling effect $\left(15^{\circ} \mathrm{C}\right.$ per $0.1 \mathrm{~s}$ of spraying time) without considering the additional effects due to buildup, film boiling and chemical reactions with the molten metal; b) the cooling medium is assumed to have a constant temperature in the channels as well as a constant heat transfer coefficient regardless of possible scale deposits; c) the secondary heat transfer mechanisms, such as conduction and convection to the surrounding air, are neglected; d) only one process cycle is simulated, even though a thermal steady state is expected to be achieved in as many as 10-15 cycles; and e) the metal viscosity is assumed to depend only on temperature, thus neglecting additional effects such as turbulence and multiphase flow (liquid, solid, vapor, and entrapped gas).

\subsection{Experimental tests}

As discussed in the next section, the simulation has helped establish tentative priorities among the solutions that are typically suggested to reduce the cold flow defects. To confirm these insights, process tests were performed under different settings of the die-casting machine. Cast parts were inspected to estimate the effects of the process parameters on the number of defects. Although limited to a specific part geometry, these effects were interpreted based on concepts that could also apply to a broader class of zinc die castings.

The tests were conducted using the same die and process settings as those in the early production runs. Three process parameters were analyzed as possible influence factors: a) fast shot plunger velocity $v$, which determines gate velocity and fill time for a given gate area; b) average temperature of the die surface, which is indirectly determined by the type of cooling medium used for the cover die half and the associated temperature $T$; and c) quantity of die lubricant sprayed on the die surface after ejection, which is indirectly determined by the spraying time $t_{\mathrm{L}}$ for a given number and arrangement of spray nozzles. For each factor, two levels were approximately selected as the extremes of its acceptable interval. For each combination of levels, the machine was operated for 15 transient cycles to reach thermal stability and for additional 5 cycles to produce sample castings. In each casting, the number of cold flow defects was evaluated at the four positions $\mathrm{P}$ already noted as critical in Fig. $4 \mathrm{a}$. The entire experiment resulted in a full factorial plan with 4 factors, as described in Tab. 1, for a total of 32 treatments and 160 observations. A complete randomization of the test sequence could not be achieved because it would have required an unreasonable number of starts and transient cycles on the machine.

For a quantitative evaluation of the cold flow defects, digital images of the samples were collected under repeatable lighting conditions at the four positions. Except for positioning errors, each image reproduced the same area of the selected zone on the part surface (e.g., zone 3 in Fig. 5a). The images were analyzed using a software procedure, which counted the pixels with a lightness value (arithmetic mean of the maximum and minimum RGB values) at a given difference to a reference value for the same zone (Fig. $5 b$ ). The percentage $D$ of those pixels over the part surface in the image is selected as an index of the number of defects. 


\section{Results}

The results of the simulation and the experimental tests on the reference case are reported below along with a discussion of how they can lead to possible strategies to reduce the cold flow defects.

\subsection{Simulation results}

The simulation model has been used to evaluate certain parameters over the entire cavity and compare them to the actual distribution of the defects. A first observation was related to the metal velocities at the beginning of the fill. Fig. 6a indicates that the gate velocity is relatively low $(5-10 \mathrm{~m} / \mathrm{s})$, which is most likely due to a delayed fast shot; this can result in a long fill time and a high turbulence once the fast shot stage begins. Then, as indicated in Fig. $6 \mathrm{~b}$, the gate velocity increases to extremely high values (over $60 \mathrm{~m} / \mathrm{s}$ ), which could cause splashing and die erosion; this is most likely due to undersized gate cross-sections. It can also be noted that a few of the vacuum channels are clogged too early by the metal from the nearby gates; the poor air venting could influence the flow due to backpressure and oxidation. All of the above issues (long fill, turbulence, splashing, and oxidation) are possibly related to the cold flow defects, such as shotting and cold shuts, which can thus be predicted from the first steps of the simulation.

At the end of the fill, it was expected that a few parameters would have abnormal values in the defective areas of the casting. This result was verified for the following outputs: a) air pressure and air volume fraction in the molten metal, possibly related to the backpressure and turbulence; b) flow length from the sprue, possibly related to the temperature drop and premature solidification; and c) average time of contact for the melt with air, possibly related to excessive oxidation. However, none of outputs demonstrated distributions correlating to the actual location of the defects, which indicates that the involved issues have a secondary influence on the occurrence of the cold shuts.

Fig. 7 presents a simulated distribution of the metal temperature at the end of the cavity fill, which is estimated to occur after $25 \mathrm{~ms}$. This parameter appears to be clearly correlated with the defects observed in the samples. The temperature is still close to the initial $420^{\circ} \mathrm{C}$ everywhere, except in zones $1,2,3$ and 4 of Fig. $4 \mathrm{a}$, where it decreased to approximately $405^{\circ} \mathrm{C}$, where streams from different gates meet, and approximately $395^{\circ} \mathrm{C}$, where heat removal is enhanced by a higher surface-area-to-volume ratio. This result suggests that premature solidification is a better indication for cold flow defects compared to other issues (oxidation, entrapment of lubricant residues, backpressure, and turbulence). A less easy task is to establish a threshold for the metal temperature with respect to the occurrence of defects, which may possibly be higher than the liquidus temperature $\left(386^{\circ} \mathrm{C}\right)$ due to simulation uncertainties. A few cold shuts are located where the molten metal has used only a small fraction of its superheat $\left(15^{\circ} \mathrm{C}\right.$ out of nearly $\left.35^{\circ} \mathrm{C}\right)$.

The inconsistency between the temperature values and the defects from the premature solidification can be explained by the above discussed secondary effects and specifically the turbulence induced in the flow by the impacts and bends. As revealed by the evolution of the metal temperature during the fill in zone 4 (Fig. 8), collisions between the streams from different gates causes backfills, which delay the draining of molten metal into the overflow. In addition to turbulence, this effect can promote the formation of droplets, which tend to freeze rapidly and may thaw again when reached by the primary flow.

Thus, die cooling is likely to be a key driver for the cold flow defects. Injection pressure and plunger velocity may be additional influencing factors because they determine the operating point of the machine-die system and keep it away from critical conditions. When trying to verify the relevance of these parameters using simulation, different levels of operating pressure (22 and $26 \mathrm{MPa}$ ) were found to produce extremely similar flow patterns and temperature distributions. However, the relevance of the plunger velocity was confirmed through simulations with fast shot velocities of $0.6 \mathrm{~m} / \mathrm{s}$ (Fig. 9a) and $2 \mathrm{~m} / \mathrm{s}$ (Fig. 9b), which resulted in different gate velocities. The distributions of the metal temperature at the end of the fill are extremely 
different, and potential critical conditions are detected at the low velocity. At equal cooling parameters, the temperatures in the flow junctions (circled in the figures) decrease on average by nearly $5^{\circ} \mathrm{C}$ for a $0.5 \mathrm{~m} / \mathrm{s}$ decrease in the plunger velocity.

\subsection{Experimental results}

The number of surface defects measured on all of the samples in the experimental plan is presented in Fig. 10 and Fig. 11 for two levels of lubricant spraying time. Each plot includes the individual values and the 95\% confidence intervals of $D$ at the four positions.

Comparing the left and right plots for each temperature level, it is clear that velocity has the largest effect among the analyzed factors. An increase in the velocity yields a reduction in the cold shuts because the molten metal has less time to cool and solidify through the gates and within the cavity; a secondary reason may be the additional heat supply in the metal due to the higher energy losses. Although it is less effective, cold flow defects can also be controlled by reduced die cooling. Although the chance of premature solidification depends on both the internal and external cooling, a lower amount of die spray is preferable because it has the additional effect of reducing metal contamination.

Comparing the top and bottom plots for each velocity level, an interesting interaction effect can be noted. If the fill time is kept short using a fast injection (right plots), a higher die temperature from the weaker internal cooling yields a considerable reduction in the defects. Conversely, with a longer fill time due to a slow injection (left plots), an increase in the die temperature can be detrimental to the surface integrity. Although a possible explanation of such behaviour using geometrical considerations will be provided later, it can be noted that in the latter condition, a reduced amount of the die spray (otherwise nearly irrelevant) slightly improves the surface integrity, most likely due to lower contamination issues.

An inspection of the individual plots allows a comparison of the defects in different positions, thus helping include the part geometry in the interpretation of the results. On average, the edge close to the gates on the central aperture (zone 1) is the most affected by the flow defects while the narrow web on the rear (zone 3) has a comparatively better surface quality in spite of its unfavourable surface-area-to-volume ratio. Considering the order in which the molten metal reaches the four zones based on the simulation $(1,3,2,4)$, it is doubtful that the above evidence is related to the position of the individual zones. Thus, it can be conjectured that the surface quality is affected by the turbulence, which is most likely lower in the web than in the main cosmetic surfaces (zones 2 and 4) due to the smaller cross section and higher at the edges due to the abrupt change in thickness from the gates to the part walls.

Although the random variation of the values within each treatment is notably small, statistical tests were performed to confirm the significance of the factors and their interactions. An analysis of the variance (Tab. 2) has indicated that the two factors $v$ and $T$ have significant individual effects and pairwise interaction while $t_{\mathrm{L}}$ has only a significant interaction with $T$. Despite the failure of the normality test on the residuals, which is most likely due to the non-random effect of $P$, the test satisfies all remaining statistical conditions for validity (homogeneity of variance by Levene's test, lack of dependence on fits and individual factors, and lack of autocorrelation).

For a deeper analysis of the geometrical effects, four subplans were extracted from the entire experimental plan that only considered tests conducted with a minimum die spray $\left(t_{\mathrm{L}}=0.1 \mathrm{~s}\right)$, which are more consistent than the typical settings. Each subplan includes half of the tests performed on each zone and is a $2^{2}$ full factorial plan for the two factors $v$ and $T$. The analyses of the variance for the individual subplans satisfy all needed conditions of the residuals (normality by Anderson-Darling's test, homogeneity of variance by Bartlett's test, lack of dependence on fits and factor values, and lack of autocorrelation). In nearly all of the cases, the primary effects and the interaction of the two factors were found to be significant. The minimum 
number of cold flow defects is invariably associated to the same setting, corresponding to a weak internal cooling and a short fill time. However, the interaction plots in Fig. 12, which compare the means at each combination of temperature and velocity, show slightly different patterns in the four regions of the casting. The wide walls in zones 2 and 4 indicate a better surface quality at a higher die temperature irrespective of the fill time: this behaviour is what is expected, even though the interaction between $v$ and $T$ may or may not be significant without any easy explanation. Conversely, zones 1 and 3 indicate the negative effects of a weaker cooling with a longer fill time, hence noted in the entire plan; their common geometric property is a higher surface-area-to-volume ratio, which is related to the cooling rate and may help explain the above singularity.

\section{Validation and additional insights}

Although the need to reduce the solid fraction at the end of the fill is widely recognized in literature, simulation and experimental results help select the right approach to reach this goal. Specifically, three clues have been gathered: a) reducing fill time appears to have a higher priority than increasing the die surface temperature; b) spray cooling should be kept to a minimum, thus the die surface temperature is to be primarily controlled by the design of the cooling channels and the related parameters; and c) metal streams with narrow front sections are most likely less affected by the premature solidification from the flow turbulence.

In an attempt to validate these criteria, the case study has been further developed for a second version of the boiler casing with similar sizes and form details (Fig. 13). Based on the issues raised by the first version, the cold flow defects were expected to be somewhere in the primary wall (zone 1') and in two critical form details (zones $2^{\prime}$ and $3^{\prime}$ ). The opportunity to set up the process for a new product is allowed to repeat the entire design cycle, verify that the flow defects can be reduced through the process choices, and collect further guidelines to be applied to the part and die design.

\subsection{Process improvement}

The increase in the flow rate through the gates can be noted as a priority based on the simulations and experimental tests. For a new die, this objective cannot be achieved through an increase in the gate velocity because additional defects from the die erosion would offset the reduction in the cold flow defects. A more proper action is to increase the total gate area and set the pressure and plunger velocity so that the gate velocity is well within its acceptable interval (lower bound for flow atomization, and upper bound for limited die erosion). For the part studied, the additional edge length available for gating on the central aperture allowed the gate area to increase by approximately $50 \%$ without increasing the gate thickness, thus avoiding additional trimming difficulties.

The gating system for the new die retained the basic configuration of the previous version to avoid additional concerns for part quality (e.g., increased flow distances, visible gate vestiges, poor air venting, and obstructions to the metal flow). The detailed gate design required three primary iterations using simulation to predict the possible flow and cooling problems during the cavity fill. In the first iteration, the number of gates was increased to five to allow a direct fill of zone 4, which is critical for surface appearances; as an alternative, as few as three gates would have involved in stagnation problems and trimming difficulties due to the larger gate widths. Therefore, the metal temperature was found to be more uniform over the entire cavity but the flow was still poorly balanced and indicated excessive velocities from the gates near zone 3 (Fig. 14a and Fig. 14b at different times during the fill) as well as early clogging of the nearby vacuum valve. In the second iteration, the profile of each gate was redesigned in an asymmetric shape, thus improving the flow balancing; however, zone 1 was still affected by the air entrapment and turbulence problems. These 
were solved in the third iteration by introducing a slight asymmetry in the angular locations for all of the gates, which also allowed the overflows to fill earlier and reduce the additional turbulence due to the flow impacts.

The cooling channels were designed with the primary objective of avoiding hot spots, which were previously located at the bosses and ribs on the bottom side of the casting. The reason behind this selection is to avoid an intense spray cooling in those regions, which is consistent with the above discussed criterion. A few simulation iterations suggested the need for an additional fountain on the ejector die half.

As a result of the design selections in the gating and cooling systems, the simulation confirmed a considerably uniform distribution of the metal temperature at the end of the fill (Fig. 15). The cold spots were only predicted in zone 3 , where a lower number of cold flow defects had been observed in the experimental tests and explained as a beneficial side effect of the narrow flow sections. The gate velocities were estimated at approximately $45 \mathrm{~m} / \mathrm{s}$, which is far from the acceptability limits and yet allows the cavity to completely fill in $14 \mathrm{~ms}$ and solidification to occur in approximately $2 \mathrm{~s}$. Consistently, the castings produced by the new die demonstrated a significant improvement in the surface integrity. As indicated in Figs. 16 a), b) and c), the flow defects were nearly absent in all zones highlighted in Fig. 13. As it can be noted in Fig. 15, the simulated temperatures at the end of the fill in the same regions of the casting are well above $415^{\circ} \mathrm{C}$, a safety level compared to the defective areas in the first version of the casting (Fig. 7). The new process resulted in a negligible rate of rejects.

\subsection{Design for surface integrity}

The design of die castings must follow well-known rules to avoid structural defects and cost overruns. The issues faced during the design of the gating system allowed the identification of additional rules for the reduction of cold flow defects on parts with special aesthetic requirements. As a first consideration, the balancing of metal flows from different gates should be given careful consideration. This need has already been noted in Fig. 14b, where defects from excessive flow atomization were predicted from the high velocities at certain gates. Similar effects are likely to arise when the gates are placed on multiple planes, which are common in the presence of stepped parting lines; in addition to trimming difficulties, often cited in literature, this may involve different flow distances from different gates, with the possibility of excessive energy losses occurring from certain gates. Gate balancing can help achieve smooth junctions among the flows, at least in those regions of casting surface where appearance is critical (Fig. 17a); if the gate areas are incorrectly selected, turbulence due to splashes and backfills can be expected (Fig. 17b). For the same reason, as already discussed in Fig. 8, flows should never meet perpendicularly to the overflow gates.

Assuming that the junctions between the opposing streams need careful attention, their source is typically identified in the branching of the flow at cores or similar obstructions. The case study has indicated that preferential flow paths are additional sources, even within an individual stream from a gate. These can occur due to the velocity gradients from a tangential runner, which is close to the part edges (Fig. 18a) as well as the presence of particular form details in the casting; these include stepped edges where the molten metal runs faster due to restricted flow sections (Fig. 18b) and corners where metal fluidity tends to increase due to the locally higher die temperatures (Fig. 18c). Such effects are noted in the simulation, as indicated in the rightmost part of Fig. 14b, where the flow appears to move forward at the corners and the edges.

Other critical features to be considered are thick walls directly connected to the gates, as in zone 1 of Fig. 4a, where the flow turbulence has been noted on both versions of the casting. The simulation of the metal temperature and the velocity vectors indicates that the sharp increase in the thickness from the gate to the wall $(0.45$ to $3 \mathrm{~mm}$ ) causes a separation of the boundary layer (Fig. 19a) followed by a turbulent backfill (Fig. 19b). Furthermore, it has been noted that additional turbulence can occur due to multiple separations of the boundary layer at sharp bends close to a gate (Fig. 19c). To avoid them, the flow should be slowed down 
through a proper choice of the bend angles (Fig. 19d), a reduction in the gate velocity (Fig. 19e), or design of non-functional features, such as ribs to intercept the flow (Fig. 19f). If these solutions are not feasible, separations can still be avoided by changing the location of the gates (Fig. $19 \mathrm{~g}$ ).

Based on a well known design rule, the gates should be located on straight edges to allow an easy removal from the casting. This is also advisable for a reduction of the cold flow defects because it allows the tangential runners to be widened to properly direct the melt streams and reduce the occurrence of weld lines. When straight edges are not available, positioning the gates on high-curvature edges should be avoided. In such cases, the tapered sections required to control the flow direction would impose an awkward profile where the boundary layer separation and backfill would be inevitable (Fig. 20a, see also simulation results in Fig. 6a); this would result in air entrapment as well as turbulence and pressure drop with the risk of cavitation for the zinc alloys. A redesigned profile would avoid this problem (Fig. 20b) at the price of increased material loss and additional trimming difficulties.

\section{Conclusions}

The study of an industrial case using process simulation and experimental tests has led to the following guidelines for the reduction of cold flow defects in zinc die castings:

1) Simulation can help predict the occurrence of the cold flow defects. The basic condition that must be verified for this purpose is a uniform distribution of the metal temperature at the end of the cavity fill. However, temperature values seem to be less meaningful due to several sources of uncertainty (e.g., difficulty in including spray cooling in the simulation model). A secondary effect to be considered is the additional turbulence arising from the preferential flow paths, impacts between the opposing streams, delayed filling of the overflow wells, and boundary layer separation next to the gates and bends.

2) Among the possible criteria related to the process parameters, the reduction in the fill time appears to have higher priority over the reduction of both the internal and external die cooling. When the fill time is not short enough, a weaker internal cooling could further worsen the surface integrity in those regions of the casting where a higher temperature drop is expected due to geometrical reasons. Such regions would otherwise involve less turbulence due to smaller flow sections, and thus show reduced numbers of the cold flow defects compared to the wider wall surfaces.

3) In the design of the die, the increase in the total gate area is an effective choice to reduce fill time without increasing gate velocity, avoid unfavourable side effects (gas porosity related to turbulence, shrinkage porosity at gates), and the potential margins for increasing the gate width should be sought to keep the gate thickness below critical values. The location and profile of the tangential runners can also avoid splashes and vent obstructions by properly directing the melt streams. The cooling channels must be designed to avoid the formation of hot spots and thus reduce the amount of spray cooling. The successful application of the above criteria can be easily verified through process simulation.

4) Available design-for-manufacture rules for die cast components should be extended by considering potentially critical situations for the cold flow defects. These include long flow distances, stepped parting lines, high-curvature leading edges, thick walls next to gates, multiple bends, and those feature that tend to create preferential flow paths (e.g., corners, edges next to gates, and stepped edges).

Although they are derived from a single case study, the above criteria can be applied to a wider range of zinc castings with high aesthetic requirements. To better understand their advantages and limitations, these criteria are currently being verified on different part geometries and die configurations, which could help 
identify further issues that occur with more complex castings or particular form details. Future experimental investigations will include additional variables that were kept constant in this study (e.g., the composition and the initial temperature of the alloy) as well as a higher number of levels at least for the variables related to fill time. An additional objective is the reduction of the uncertainty on the simulation results, which will be pursued through more accurate models for die spray and heat transfer in cooling channels. The temperature measurements on the die surfaces will help evaluate and compensate the remaining systematic errors so that the actual values of the simulation parameters could be used in the prediction of the flow defects.

\section{Acknowledgments}

The authors are grateful to the several people involved in the project at Bruschi SpA for their help and support.

\section{Compliance with ethical standards}

This research was internally funded at Bruschi SpA and received no specific grant from any funding agency. The authors declare that they have no conflict of interest.

\section{References}

[1] ASTM B86 (2013) Standard specification for zinc and zinc-aluminum (ZA) alloy foundry and die castings. ASTM International, West Conshohocken, PA

[2] ASTM B252 (1992) Standard guide for preparation of zinc alloy die castings for electroplating and conversion coatings. ASTM International, West Conshohocken, PA

[3] Andresen B (2005) Die casting engineering: a hydraulic, thermal and mechanical process. Marcel Dekker, New York

[4] Vinarcik EJ (2003) High integrity die casting processes. John Wiley and Sons, New York

[5] Vv.Aa. (2012) NADCA product specification standards for die casting. Chapter 7: Quality assurance. North American Die Casting Association, Wheeling, IL

[6] Walkington W.G. (2003) Die casting defects: troubleshooting guide. North American Die Casting Association, Wheeling, IL

[7] Titley J. (2012) Zinc diecasting defects: their cause and elimination. Foundry Trade J 2:54-57

[8] International Zinc Association (2014) Die casting topics. http://www.coezinc.com/. Accessed 03 November 2014

[9] Kuwazuru O, Murata Y, Hangai Y, Utsunomiya T, Kitahara S, Yoshikawa N (2008) X-ray CT inspection for porosities and its effect on fatigue of die casr aluminium alloy. J Solid Mech Mater Eng 2:1220-1231

[10] Okayasu M, Yoshifuji S, Mizuno M, Hitomi M, Yamazaki H (2009) Comparison of mechanical properties of die cast aluminium alloys: cold v. hot chamber die casting and high v. low speed filling die casting. Int J Cast Met Res 22:374-381

[11] Lumley R, Deeva N, Gershenzon M (2011) An evaluation of quality parameters for high pressure die castings. Int J Metalcasting 5:37-56

[12] Mitterer C, Holler F, Üstel F, Heim D (2000) Application of hard coatings in aluminium die casting: soldering, erosion and thermal fatigue behaviour. Surf Coat Technol 125:233-239

[13] Zhu Y, Schwam D, Wallace JF, Birceanu S (2004) Evaluation of soldering, washout and thermal fatigue resistance of advanced metal materials for aluminum die-casting dies. Mater Sci Eng A 379:420-431 
[14] Campbell J (2003) Castings. 2nd ed. Butterworth-Heinemann, Oxford, UK

[15] Neff DV (2014) Improving die casting melt quality and casting results with melt quality analysis and filtration. Metaullics Systems Co., Solon, OH. http://www.pyrotek.info/. Accessed 03 November 2014

[16] Han Q, Xu H (2005) Fluidity of alloys under high pressure die casting conditions. Scr Mater 53:7-10

[17] Goodwin FE, Zhang K, Filc AB, Holland RL, Dalter WR, Jennings TM (2007) Development of zinc die casting alloys with improved fluidity: progress in thin section zinc die casting technology. Proc. NADCA Metalcasting Congress, Houston, TX

[18] Helenius R, Lohne O, Arnberg L, Laukli HL (2005) The heat transfer during filling of a high-pressure die-casting shot sleeve. Mater Sci Eng A 413-414:52-55

[19] Sadeghi M, Mahmoudi J (2012) Experimental and theoretical studies on the effect of die temperature on the quality of the products in high-pressure die-casting process. Adv Mater Sci Eng 434605

[20] Iwata Y, Dong S, Sugiyama Y, Iwahori H (2013) Effects of solidification behavior during filling on surface defects of aluminum alloy die casting. Mater Trans 54:1944-1950

[21] Ferreira JC (2006) A study of advanced die-casting technology integrating CAD/RP/FEA for Zn castings. Int J Adv Manuf Technol 31:235-243

[22] Wei H, Chen YS, Shang HM, Wang TS (1996) The study of flow pattern and phase-change problem in die casting process. Proc. AIAA Thermophysics Conference, New Orleans, LA

[23] Zamora R, Hernandez-Ortega JJ, Faura F, Lopez J, Hernandez J (2008) Experimental investigation of porosity formation during the slow injection phase in high-pressure die-casting processes. ASME $\mathrm{J}$ Manuf Sci Eng 130:051009

[24] Nikroo AJ, Akhlaghi M, Najafabadi MA (2009) Simulation and analysis of flow in the injection chamber of die casting machine during the slow shot phase. Int J Adv Manuf Technol 41:31-41

[25] Yan H, Zhuang W, Hu Y, Zhang Q, Jin H (2007) Numerical simulation of AZ91D alloy automobile plug in pressure die casting process. J Mater Process Technol 187-188:349-353

[26] Fu MW, Yong MS (2009) Simulation-enabled casting product defect prediction in die casting process. Int J Prod Res 47:5203-5216

[27] Dørum C, Laukli HL, Hopperstad OS (2009) Through-process numerical simulations of the structural behaviour of Al-Si die-castings. Comput Mater Sci 46:100-111

[28] Jin CK, Jang CH, Kang CG (2013) Die design optimization of die casting for fabrication of fuel cell aluminum bipolar plate with micro-channel through casting simulation and experimental investigation. J Mech Sci Technol 27:2997-3003

[29] Sung BS, Kim IS (2008) The molding analysis of automobile parts using the die-casting system. J Mater Process Technol 201:635-639

[30] Cleary PW, Ha J, Prakash M, Nguyen T (2006) 3D SPH flow predictions and validation for high pressure die casting of automotive components. Appl Math Model 30:1406-1427

[31] Homayonifar P, Babaei R, Attar E, Shahinfar S, Davami P (2008) Numerical modeling of splashing and air entrapment in high-pressure die casting. Int J Adv Manuf Technol 39:219-228

[32] Jarfors AEW, Rigovacca D, Payandeh M, Wessen M, Seifeddine S, Jansson P (2014) Influence of process parameters on surface appearance and roughness of a low Si containing Al-alloy in semisolid casting. Solid State Phenom 217-218:318-324

[33] Webster CAG (1995) The use of images in a language- and culture-independent expert system for diagnosing pressure die-casting defects. J Mater Process Technol 55:296-302

[34] Świllo SJ, Perzyk M (2011) Automatic inspection of surface defects in die castings after machining. Arch Foundry Eng 11:231-236

[35] Bračun D, Gruden V, Možina J (2008) A method for surface quality assessment of die-castings based on laser triangulation. Meas Sci Technol 19:1-8

[36] Norwood AJ, Dickens PM, Soar RC, Harris RA (2007) Surface temperature of tools during the highpressure die casting of aluminium. Proc Inst Mech Eng Part B 221:1659-1664 
[37] Kong LX, She EH, Gao WM, Nahavandi S, Hodgson PD (2008) Integrated optimization system for high pressure die casting processes. J Mater Process Technol 201:629-634

[38] Verran GO, Mendes RPK, Dalla Valentina LVO (2008) DOE applied to optimization of aluminum alloy die castings. J Mater Process Technol 200:120-125

[39] Yarlagadda PKDV (2000) Prediction of die casting process parameters by using an artificial neural network model for zinc alloys. Int J Prod Res 38:119-139

[40] Krimpenis A, Benardos PG, Vosniakos GC, Koukouvitaki A (2006) Simulation-based selection of optimum pressure die-casting process parameters using neural nets and genetic algorithms. Int $\mathbf{J}$ Adv Manuf Technol 27:509-517

[41] Jarfors AEW (2012) Influence of casting process parameters on surface roughness in hot-chamber die casting of AZ91D. Adv Mater Res 585:349-353

[42] Zheng J, Wang Q, Zhao P, Wu C (2009) Optimization of high-pressure die-casting process parameters using artificial neural network. Int J Adv Manuf Technol 44:667-674

[43] Bar-Meir G, Brauner N (1999) The mathematical theory of the $\mathrm{pQ}^{2}$ diagram. UMSI Research Report 99/40, Minnesota Supercomputing Institute, Minneapolis, MN

[44] Vv.Aa. (2014) Runner and gate design. The Brock Metal Company, Cannock, Staffs., UK. http://www.brockmetal.com/. Accessed 03 November 2014

[45] Tai CC, Lin JC (1998) A runner-optimization design study of a die-casting die. J Mater Process Technol 84:1-12

[46] Lin JC (2002) Selection of the optimal gate location for a die-casting die with a freeform surface. Int J Adv Manuf Technol 19:278-284

[47] Wu SH, Lee KS, Fuh JYH (2002) Feature-based parametric design of a gating system for a die-casting die. Int J Adv Manuf Technol 19:821-829

[48] Bounds S, Davey K, Hinduja S (2000) An experimental and numerical investigation into the thermal behavior of the pressure die casting process. ASME J Manuf Sci Eng 122:90-99

[49] Lin JC (2003) The optimal design of a cooling system for a die-casting die with a free form surface. Int J Adv Manuf Technol 21:612-619

[50] Clark LD, Davey K, Hinduja S (2001) Novel cooling channel shapes in pressure die casting. Int J Numer Method Eng 50:2411-2440

[51] Alonso Rasgado MT, Davey K, Clark LD, Hinduja S (2006) Bi-metallic dies for rapid die casting. J Mater Process Technol 175:109-116

[52] Armillotta A, Baraggi R, Fasoli S (2014) SLM tooling for die casting with conformal cooling channels. Int J Adv Manuf Technol 71:573-583

[53] Liu GW, Morsi YS, Clayton BR (2000) Characterisation of the spray cooling heat transfer involved in a high pressure die casting process. Int J Therm Sci 39:582-591

[54] Sabau AS, Hatfield EC (2007) Measurement of heat flux and heat transfer coefficient due to spray application for the die casting process. Proc Inst Mech Eng Part B 221:1307-1316

[55] Bar-Meir G, Eckert ERG, Goldstein RJ (1997) Air venting in pressure die casting. ASME J Fluid Eng 119:473-476

[56] Lee WB, Lu HY (1999) Modeling of air back pressure in die-casting dies. J Mater Process Technol 91:264-269

[57] Nouri-Borujerdi A, Goldak JA (2004) Modeling of air venting in pressure die casting process. ASME J Manuf Sci Eng 126:577-581

[58] Hernández J, López J, Faura F (2001) Influence of unsteady effects on air venting in pressure die casting. ASME J Fluid Eng 123:884-892

[59] Niu XP, Hu BH, Pinwill I, Li H (2000) Vacuum assisted high pressure die casting of aluminium alloys. J Mater Process Technol 105:119-127 


\section{Figures}
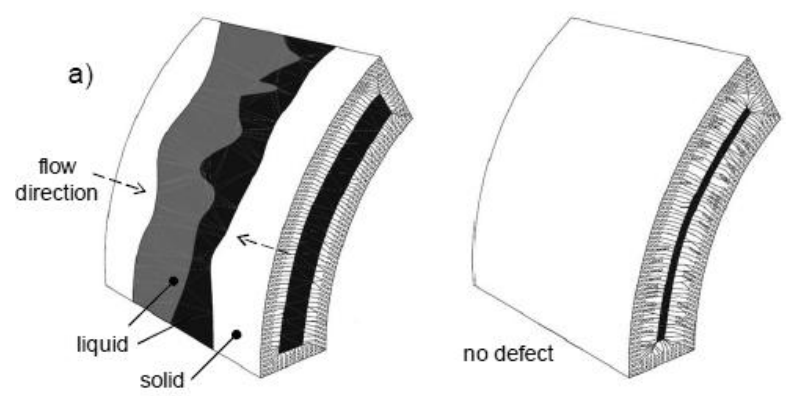

b)
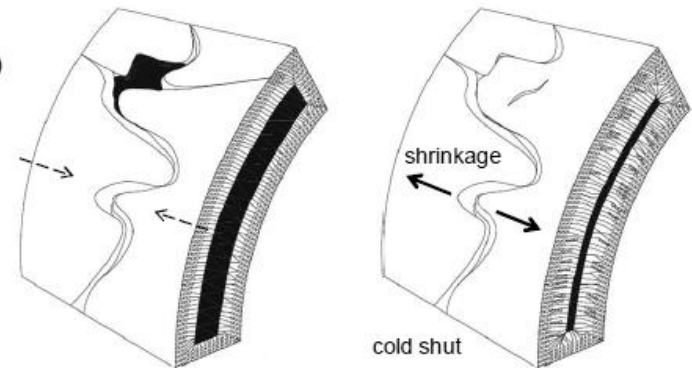

Fig. 1: Schematic of the formation for cold flow defects: a) ideal situation; and b) incorrect welding of flows
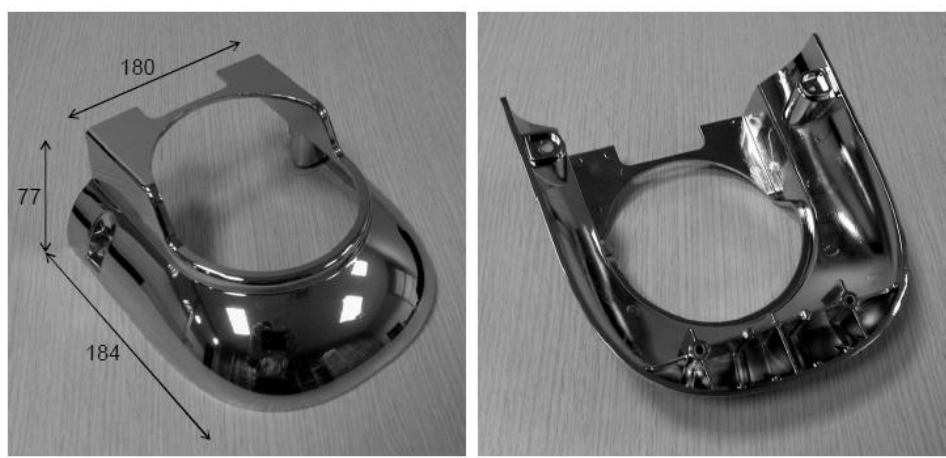

Fig. 2: Boiler casing for a commercial espresso machine (dimensions in $\mathrm{mm}$ )

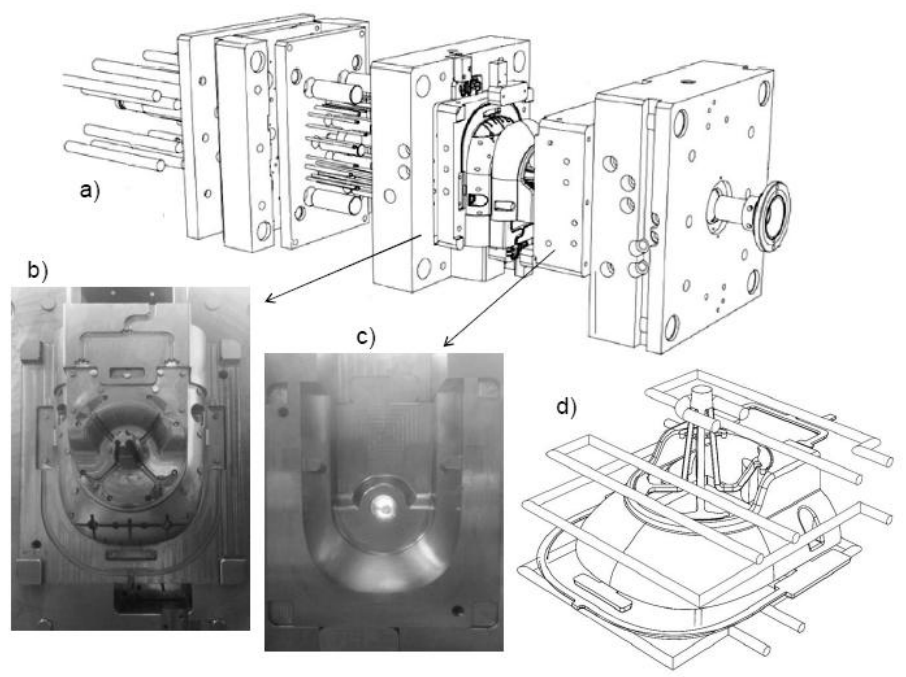

Fig. 3: Die-casting die for the boiler casing: a) die assembly; b) ejector die half; c) cover die half; and d) cooling channels 

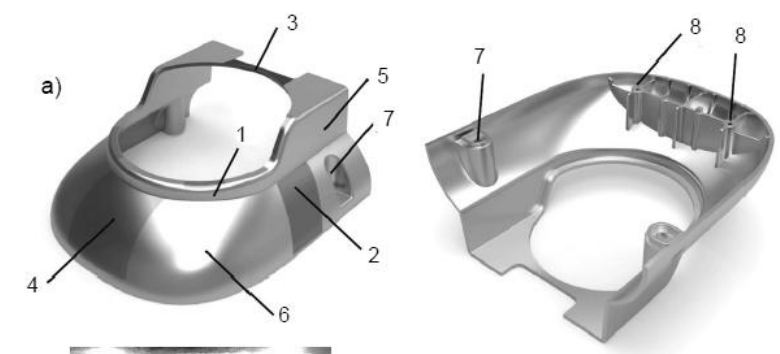

b)

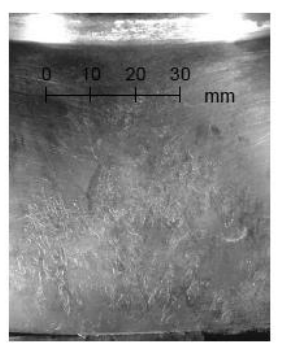

c)

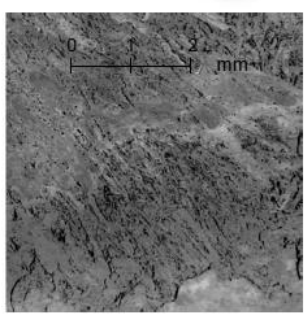

Fig. 4: Cold flow defects on the casting surface: a) defective zones; b) cold shuts in zone 4; and c) enlarged view of the cold shuts

$\stackrel{0}{1,1,1,-1} \mathrm{~mm}$

a)

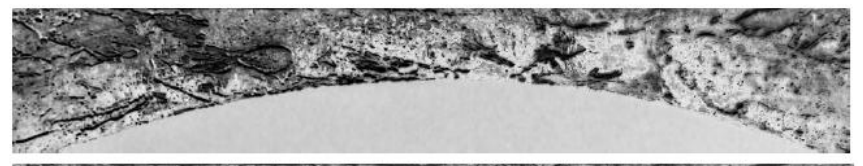

b)

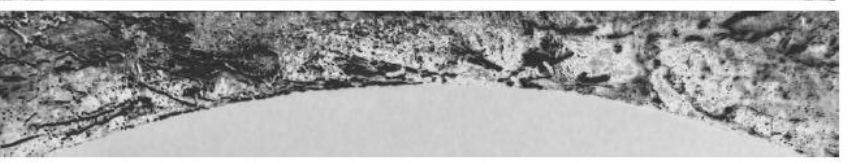

Fig. 5: Evaluation of the number of defects: a) sample image; and b) identification of the defects
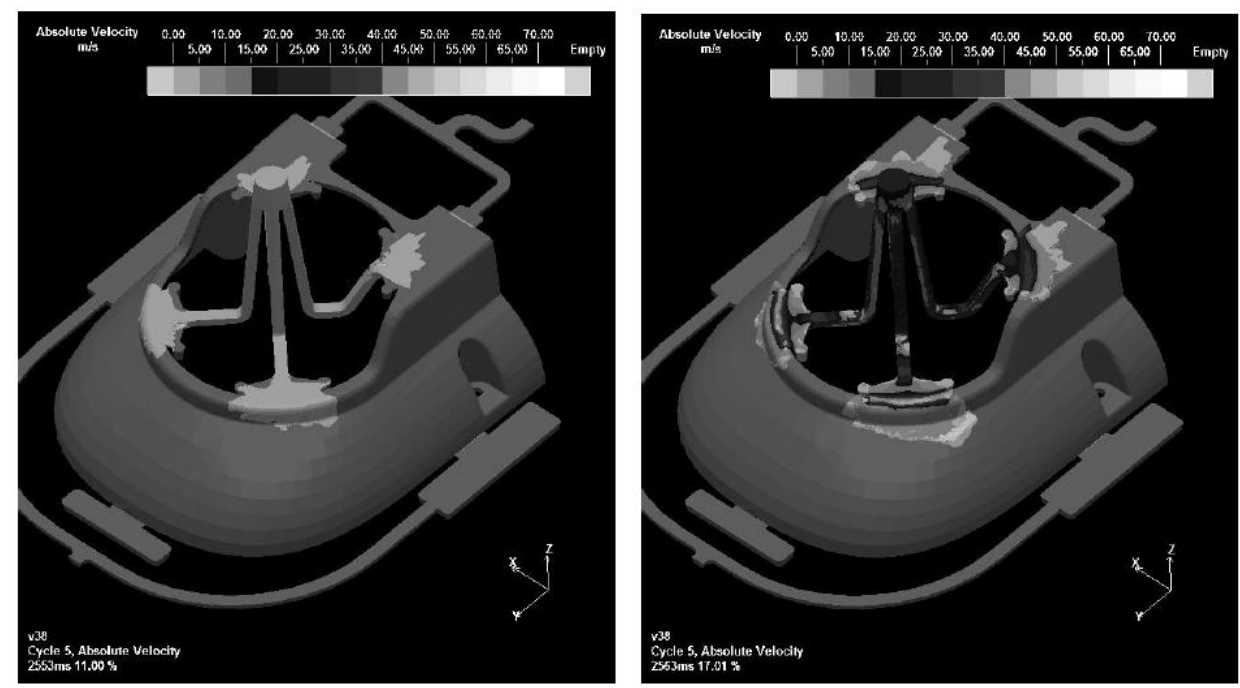

Fig. 6: Flow velocity at the beginning of the cavity fill: a) delayed fast shot; and b) excessive gate velocity 


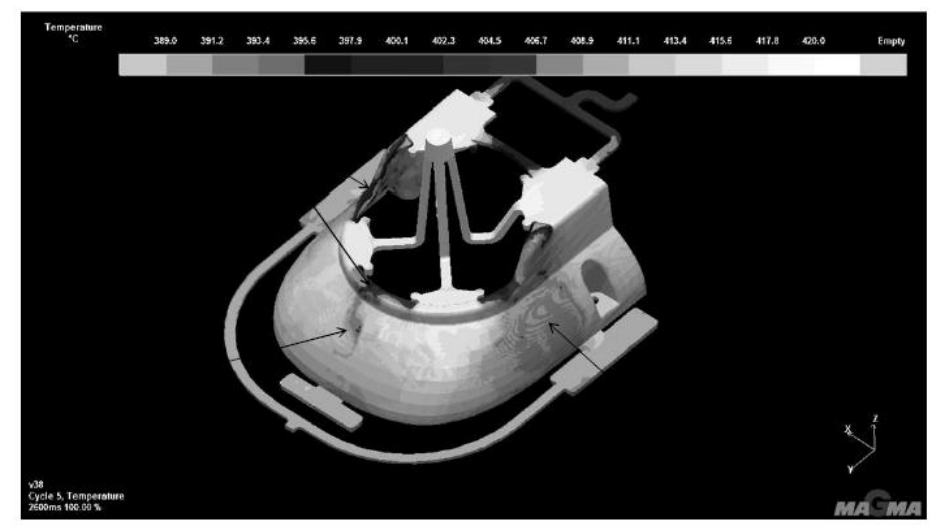

Fig. 7: Metal temperature at the end of the fill



Fig. 8: Turbulence due to impact between the streams
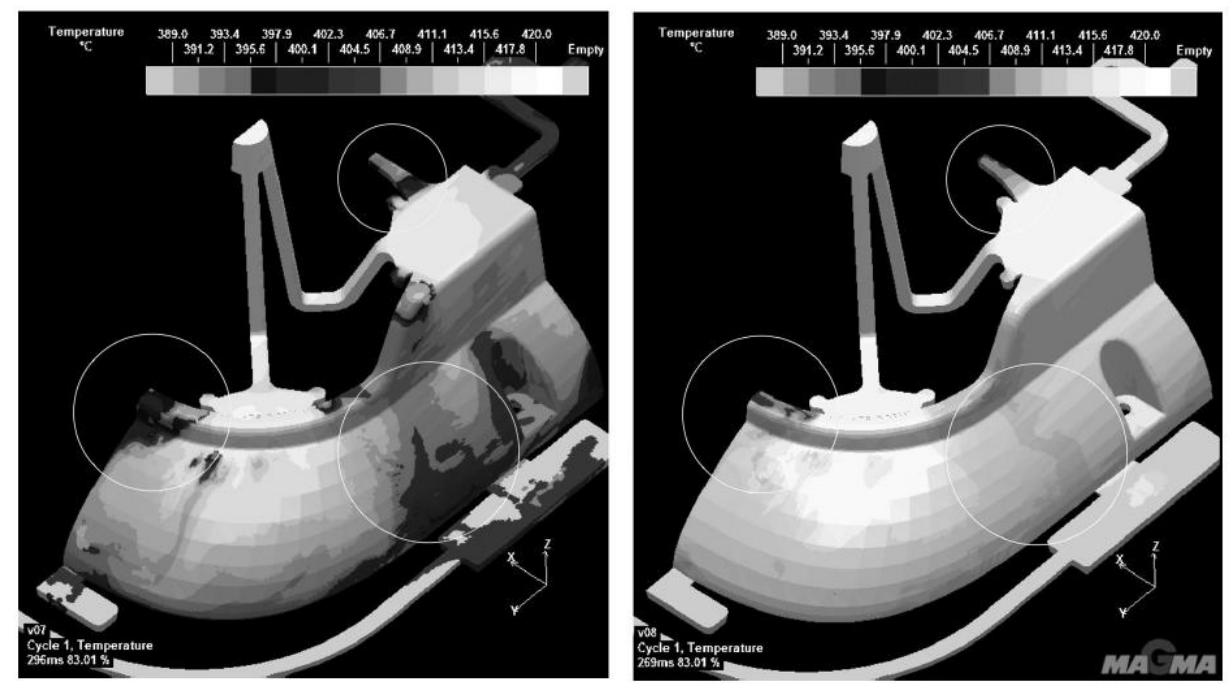

Fig. 9: Metal temperature at different injection velocities: a) low velocity; and b) high velocity 


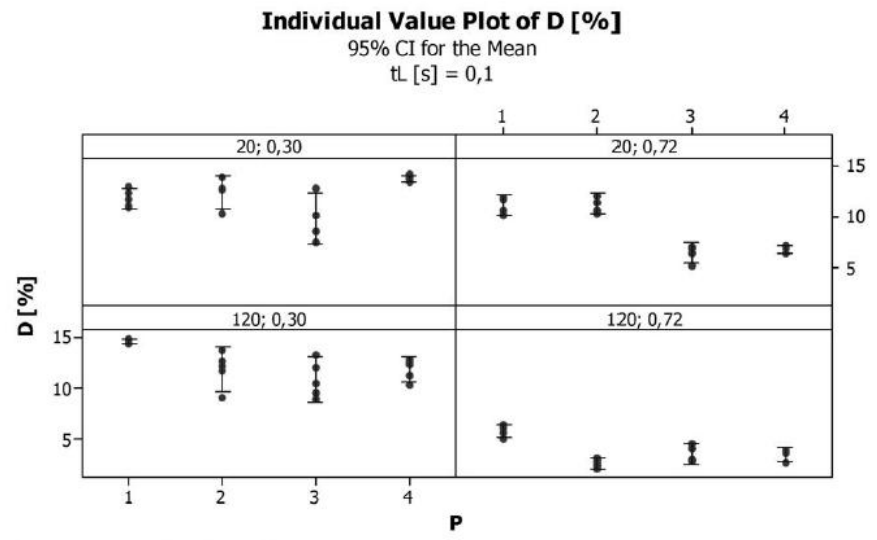

Panel variables: $\mathrm{T}\left[{ }^{\circ} \mathrm{C}\right] ; \mathrm{v}[\mathrm{m} / \mathrm{s}]$

Fig. 10: Number of defects $D[\%]$ at different positions as a function of the velocity and the temperature (minimum lubrication)

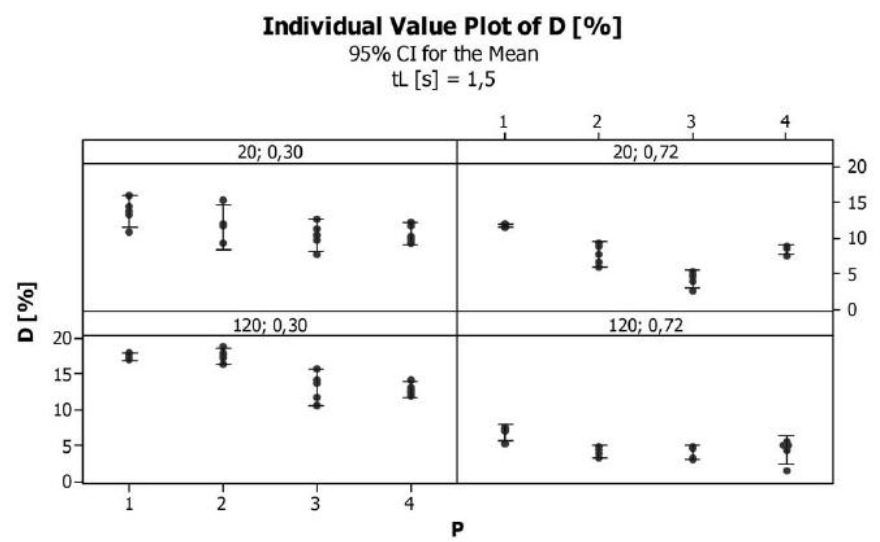

Panel variables: $\mathrm{T}\left[{ }^{\circ} \mathrm{C}\right] ; \mathrm{v}[\mathrm{m} / \mathrm{s}]$

Fig. 11: m number defects $D[\%]$ at different positions as a function of the velocity and the temperature (maximum lubrication)

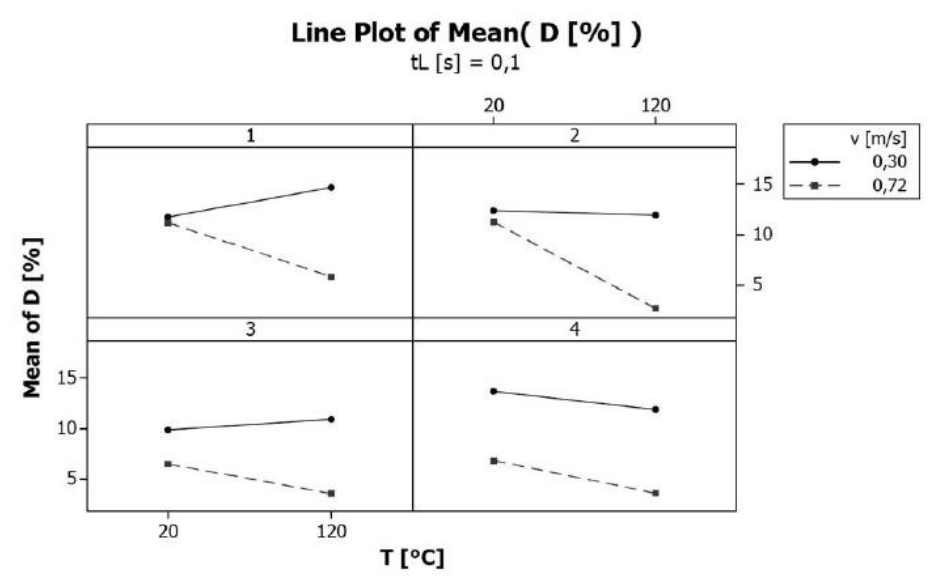

Panel variable: $P$

Fig. 12: Interaction effects on $D[\%]$ from the minimum-lubrication subplans: a) zone 1 ; b) zone 2; and c) zone $3, \mathrm{~d}$ ) zone 4 


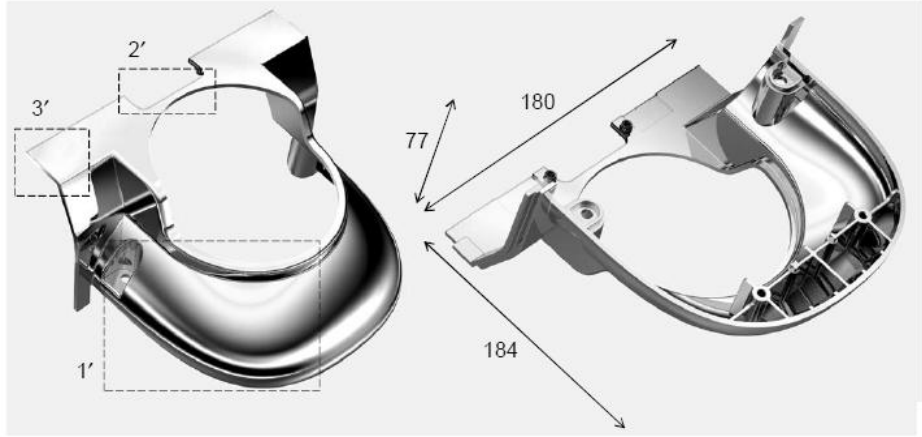

Fig. 13: New version of the boiler casing (dimensions in $\mathrm{mm}$ )
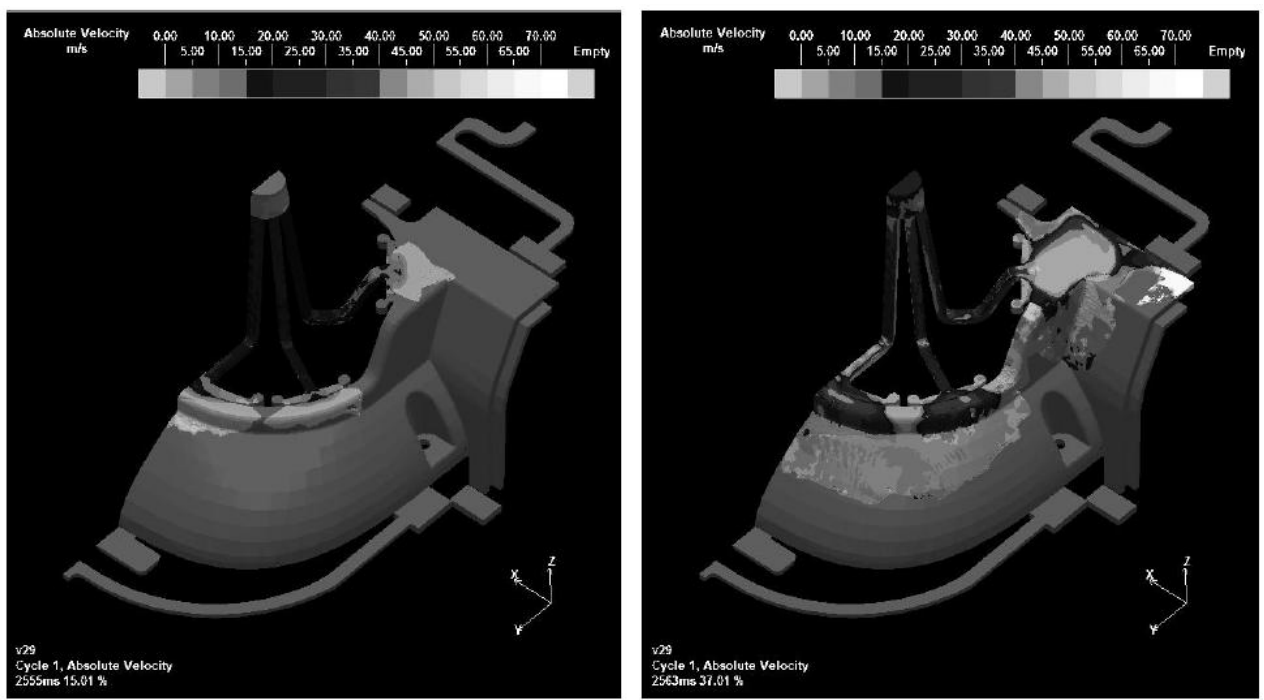

Fig. 14: Flow velocity for a preliminary design of the gating system: a) at the beginning of the fill, and b) clogging of the vacuum valve
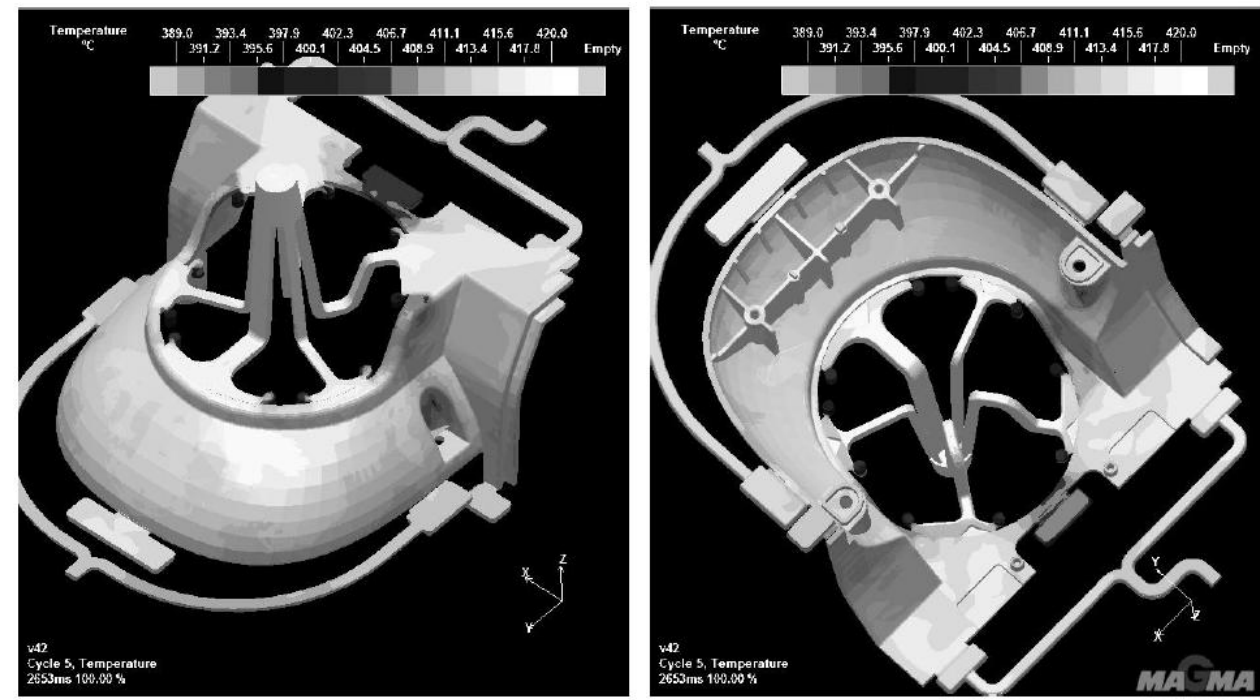

Fig. 15: Gating system for the new die and end-of-fill metal temperature 

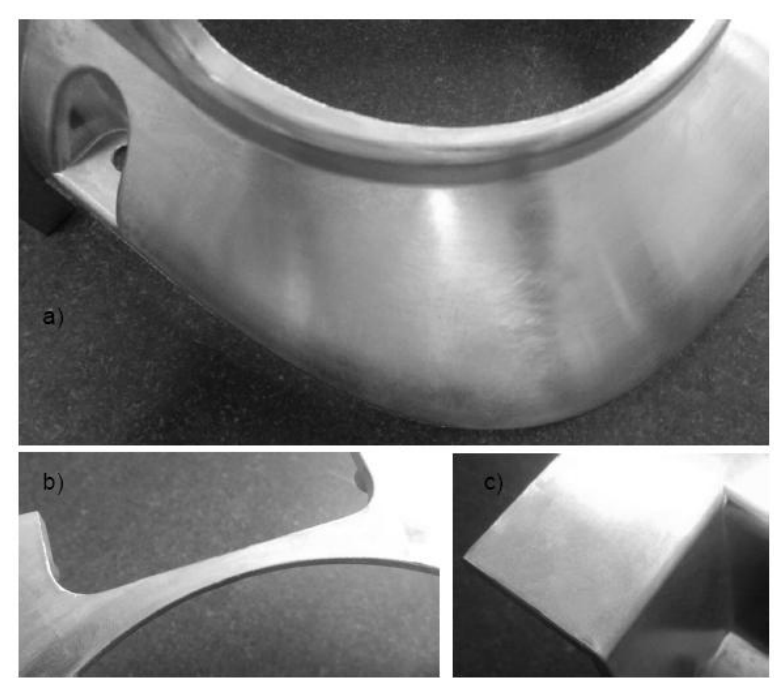

Fig. 16: Reduction in the cold flow defects on the new casting: a) zone $1^{\prime}$; b) zone $2^{\prime}$; and c) zone $3^{\prime}$

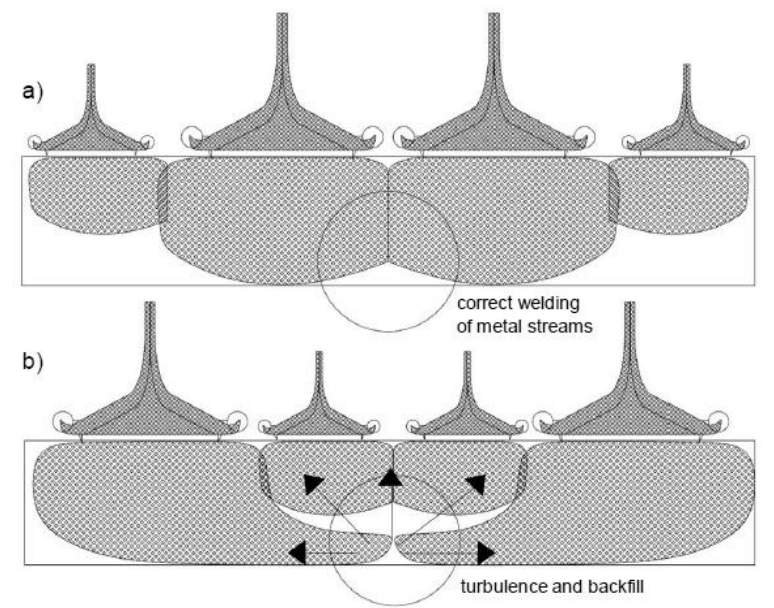

Fig. 17: Balancing the gates to avoid cold flow defects: a) correct sizing and b) incorrect sizing

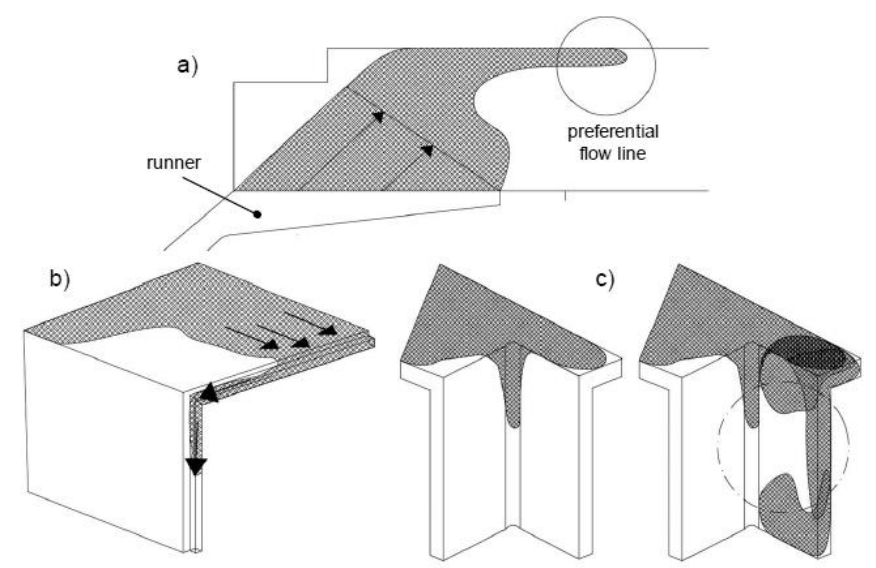

Fig. 18: Preferential flow paths: a) part edges; b) stepped edges; c) corners 


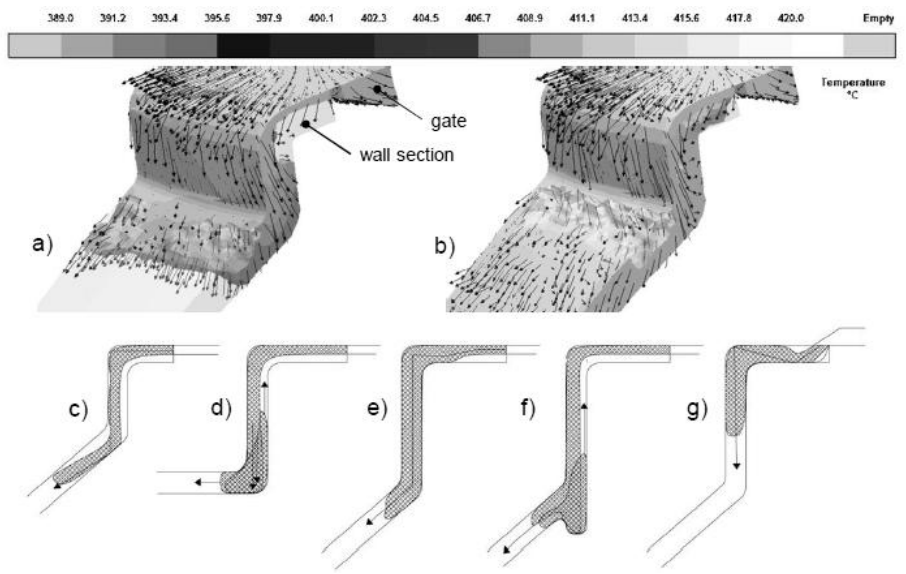

Fig. 19: Turbulence after a gate: a) layer separation; b) backfill c-d) causes of layer separation, and e-f-g) possible remedies

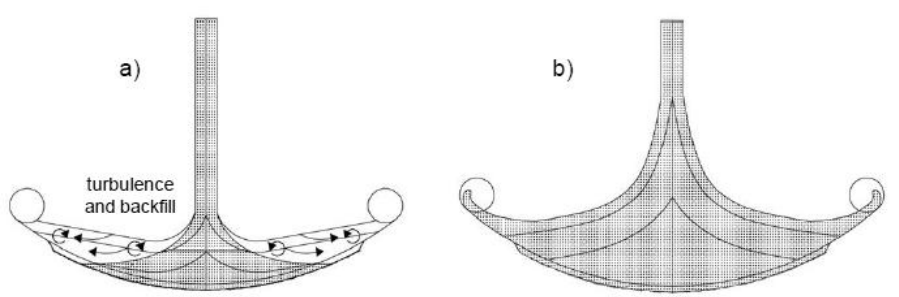

Fig. 20: Issues with gates on curved edges: a) regularly sized runner and b) oversized runner

\section{Tables}

Tab. 1: Experimental plan

\begin{tabular}{lcccl}
\hline \multicolumn{1}{c}{ Factor } & Symbol & Unit & No. levels & \multicolumn{1}{c}{ Values } \\
\hline fast shot plunger velocity & $v$ & $\mathrm{~m} / \mathrm{s}$ & 2 & $0.30,0.70$ \\
temperature of cooling medium & $T$ & ${ }^{\circ} \mathrm{C}$ & 2 & $20^{\circ} \mathrm{C}$ (water), $120^{\circ} \mathrm{C}$ (oil) \\
lubricant spraying time & $t_{\mathrm{L}}$ & $\mathrm{s}$ & 2 & $0.1,1.5$ \\
position & $\mathrm{P}$ & & 4 & $1,2,3,4$ (Fig. 4a) \\
\hline
\end{tabular}

Tab. 2: Analysis of variance in the number of defects $D[\%]$

\begin{tabular}{lcccccc}
\hline \multicolumn{1}{c}{ Source } & DF & Seq SS & Adj SS & Adj MS & $F$ & $p$ \\
\hline$v[\mathrm{~m} / \mathrm{s}]$ & 1 & 1620.24 & 1620.24 & 1620.24 & 351.91 & 0.000 \\
$T\left[{ }^{\circ} \mathrm{C}\right]$ & 1 & 37.94 & 37.94 & 37.94 & 8.24 & 0.005 \\
$t_{\mathrm{L}}[\mathrm{s}]$ & 1 & 15.90 & 15.90 & 15.90 & 3.45 & 0.065 \\
$v[\mathrm{~m} / \mathrm{s}] \cdot T\left[{ }^{\circ} \mathrm{C}\right]$ & 1 & 388.87 & 388.87 & 388.87 & 84.46 & 0.000 \\
$v[\mathrm{~m} / \mathrm{s}] \cdot t_{\mathrm{L}}[\mathrm{s}]$ & 1 & 17.07 & 17.07 & 17.07 & 3.71 & 0.056 \\
$T\left[{ }^{\circ} \mathrm{C}\right] \cdot t_{\mathrm{L}}[\mathrm{s}]$ & 1 & 70.99 & 70.99 & 70.99 & 15.42 & 0.000 \\
$v[\mathrm{~m} / \mathrm{s}] \cdot T\left[{ }^{\circ} \mathrm{C}\right] \cdot t_{\mathrm{L}}[\mathrm{s}]$ & 1 & 5.99 & 5.99 & 5.99 & 1.30 & 0.256 \\
Error & 152 & 699.82 & 699.82 & 4.60 & & \\
\hline Total & 159 & 2856.83 & & & & \\
\hline
\end{tabular}

